\title{
Concatenated Batch and Continuous Flow Procedures for the Upgrading of Glycerol-Derived Aminodiols via N-Acetylation and Acetalization Reactions
}

\author{
Davide Rigo (D), Nadia Alessandra Carmo Dos Santos, Alvise Perosa (D) and Maurizio Selva *(D) \\ Dipartimento di Scienze Molecolari e Nanosistemi, Università Ca' Foscari, Via Torino 155, 30172 Venezia, Italy; \\ davide.rigo@unive.it (D.R.); alessandra.santos@unive.it (N.A.C.D.S.); alvise@unive.it (A.P.) \\ * Correspondence: selva@unive.it; Tel.: +39-041-234-8687
}

check for updates

Citation: Rigo, D.; Carmo Dos Santos, N.A.; Perosa, A.; Selva, M.

Concatenated Batch and Continuous Flow Procedures for the Upgrading of Glycerol-Derived Aminodiols via $\mathrm{N}$-Acetylation and Acetalization Reactions. Catalysts 2021, 11, 21. https://dx.doi.org/10.3390/catal11010021

\section{Received: 1 December 2020}

Accepted: 24 December 2020

Published: 27 December 2020

Publisher's Note: MDPI stays neutral with regard to jurisdictional claims in published maps and institutional affiliations.

Copyright: () 2020 by the authors. Licensee MDPI, Basel, Switzerland. This article is an open access article distributed under the terms and conditions of the Creative Commons Attribution (CC BY) license (https: / / creativecommons.org/ licenses/by/4.0/).
Abstract: An unprecedented two-step sequence was designed by combining batch and continuous flow (CF) protocols for the upgrading of two aminodiol regioisomers derived from glycerol, i.e., 3-amino-1,2-propanediol and 2-amino-1,3-propanediol (serinol). Under batch conditions, at 80-90 ${ }^{\circ} \mathrm{C}$, both substrates were quantitatively converted into the corresponding amides through a catalystfree $\mathrm{N}$-acetylation reaction mediated by an innocuous enol ester as isopropenyl acetate (iPAc). Thereafter, at $30-100{ }^{\circ} \mathrm{C}$ and $1-10 \mathrm{~atm}$, the amide derivatives underwent a selective CF-acetalisation in the presence of acetone and a solid acid catalyst, to afford the double-functionalized (amideacetal) products.

Keywords: isopropenyl acetate; aminodiols; N-acetylation; acetalization

\section{Introduction}

3-Amino-1,2-propanediol (3-APD) and 2-amino-1,3-propanediol (2-APD, serinol) are formally classified as glycerol derivatives obtained by the replacement of a primary or a secondary hydroxyl group of glycerol with a primary amine function. Notwithstanding this categorization, no examples have been reported so far for the straightforward preparation of 3-APD and 2-APD regioisomers from glycerol. Major synthetic routes of both substrates are summarized in Scheme 1.

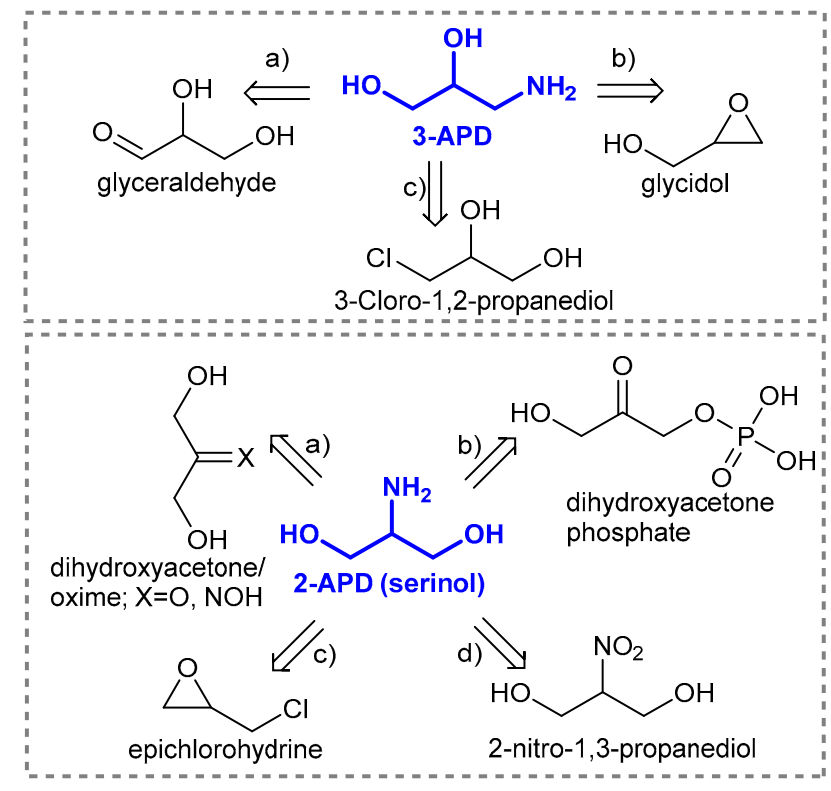

Scheme 1. Top and bottom: major routes for 3-APD and 2-APD (serinol) synthesis, respectively. 
3-APD is more often obtained from the reductive amination of biomass-derived glyceraldehyde or the nucleophilic attack of ammonia on glycidol that, in turn, is achieved by the catalytic decarboxylation of glycerol carbonate [Scheme 1, top: (a)-(b)] [1-4]. Other, less attractive procedures have proposed the use of a carcinogenic starting reagent as 3-chloro-1,2-propanediol (Scheme 1, top: (c)) [5,6].

2-APD (serinol), besides being a naturally occurring substrate, is preferably synthesized from dihydroxyacetone (DHA) which is a popular innocuous product of the partial oxidation of glycerol [7]. DHA can be used as such or in the form of oxime or phosphate derivatives (Scheme 1, bottom: (a)-(b)) [8-10]. Other approaches starts from epichlorohydrine or 2-nitro-1,3-propanediol (Scheme 1, bottom: (c)-(d)): the epicerol@technology of Solvay produces the first reactant (epichlorohydrine) straight from the catalytic chlorination of glycerol, while protocol (d) is fully based on non-renewable compounds as nitromethane and paraformaldehyde [11-13].

The compresence of three nucleophilic functions $\left(\mathrm{OH}\right.$ and $\left.\mathrm{NH}_{2}\right)$ makes both 2- and 3-APD appealing intermediates for a variety of transformations. Yet, the upgrading of these regioisomers still represents a largely unexplored area. As a part of our research program on the design of eco-friendly protocols for the valorization of bio-based products, particularly glycerol and its derivatives $[14,15]$, we were prompted to investigate new reactions for the chemoselective conversion of either the amino or the hydroxyl group of APD compounds. $\mathrm{N}$-acetylation and acetalization processes mediated by isopropenyl acetate (iPAc) and acetone were selected to this purpose, based on a literature survey and results recently published by us [14-18]. Nontoxic, commercially available, and cheap iPAc has emerged as a privileged compound since its reactions with a variety of $\mathrm{N}$ - and O-nucleophiles result in the formation of acetylated derivatives and prop-1-en-2-ol that, as an enol, quickly converts into acetone, thereby making the overall transformations irreversible. Scheme 2 describes some representative examples.

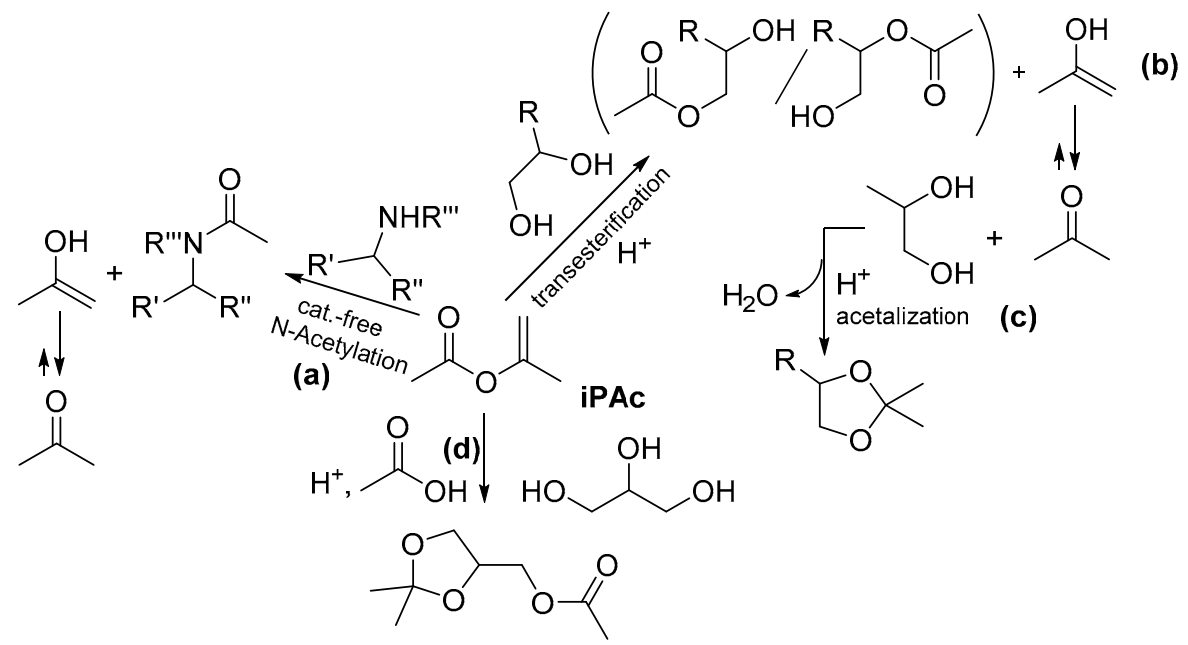

Scheme 2. Examples of $\mathrm{N}$-acetylation, transesterification and acetalization reactions mediated by iPAc (R, R', R" = alkyl, aryl; R, R"' = H, alkyl).

The N-acetylation of primary and secondary amines has been achieved with iPAc under solventless and catalyst-free conditions (path a). Of note, polyfunctional amines, such as aminoalcohols and aminophenols, have been selectively amidated while primary and secondary hydroxyls or aromatic $\mathrm{OH}$ groups were fully preserved [16]. On the other hand, the acid-catalyzed reaction of (renewable) 1,2-diols and iPAc proceeded through a tandem sequence: an initial irreversible transesterification process took place (path $b$ ), releasing acetone which then promoted acetalization on a second molecule of glycol (path c). A follow-up of this study highlighted the even more attractive case of glycerol that in the presence of a mixture of iPAc and acetone, underwent simultaneous acetylation and acetalization to provide solketal acetate in almost quantitative yields $(91 \%$, path $\mathrm{d})$. 
In light of these results, this paper reports an original two-steps approach for the conversion of APD isomers, comprised of an initial $\mathrm{N}$-acetylation reaction promoted by iPAc under batch conditions, followed by a continuous flow (CF) acetalization of the amide derivatives with acetone over a solid acid catalyst. The two processes have been first investigated separately by exploring the effect of major parameters $(T, p, t$, flow rate, and solvent) and then concatenated as shown in Scheme 3.

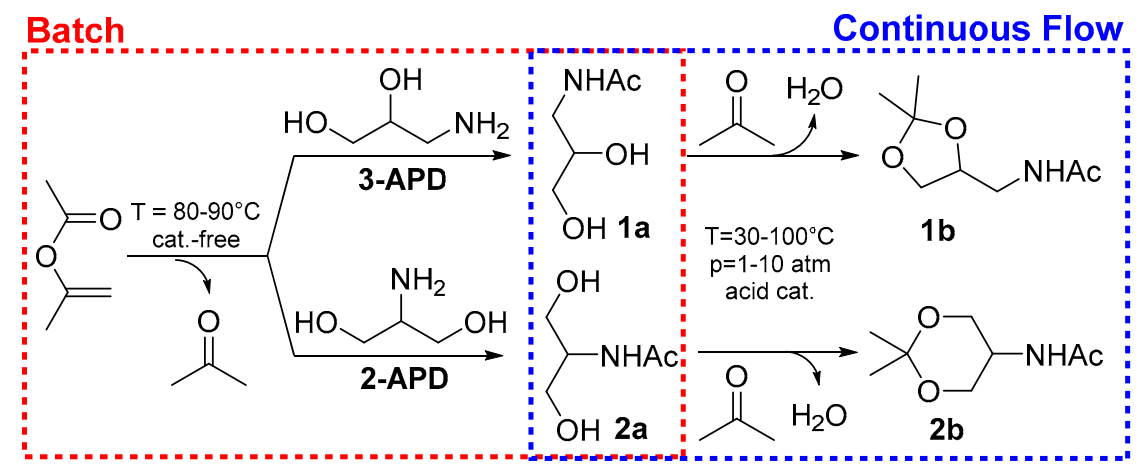

Scheme 3. Concatenated batch and CF reactions used in this work.

In the overall sequence, solutions of crude products $\mathbf{1} \mathbf{a}$ and $\mathbf{2 a}$ as obtained from the batch $\mathrm{N}$-acetylation were used without any treatment, to feed a CF-reactor for the second acetalization step. Highly (chemo)selective and quantitative reactions were achieved with selectivity towards $\mathrm{N}$-acetylated diols (1a-2a) and N-acetylacetals (1b-2b) up to $99 \%$ and $92 \%$, respectively.

\section{Results and Discussion}

\subsection{Batch Catalyst-Free N-Acetylation of 2- and 3-APD with iPAc}

The N-acetylation of 2- and 3-APD with iPAc could not be carried out under the conditions previously described for primary and secondary amines (path a, Scheme 1), because the highly polar nature of both regioisomers made them fully immiscible with iPAC and with most of conventional organic liquids. After a screening of several candidates, two solvents were identified, i.e., 1,4-dioxane and dimethyl sulfoxide (DMSO) in which the solubilities of APDs were ca 0.2 and $1 \mathrm{mmol} / \mathrm{mL}$, respectively. The lower-boiling 1,4dioxane (b.p. $=101^{\circ} \mathrm{C}$ ) was selected to start the investigation since its removal (distillation) was simpler during work-up procedures.

Temperature and reaction time. Initial experiments were performed to explore the effects of the temperature and the reaction time. A mixture of the selected APD ( $1 \mathrm{mmol})$, iPAc (1.1 equivs.), and 1,4-dioxane ( $5 \mathrm{~mL}, \mathrm{C}=0.2 \mathrm{M}$ ) was set to react at $\mathrm{T}=80-100{ }^{\circ} \mathrm{C}$ for up to $62 \mathrm{~h}$, in the absence of any catalyst. Results are described in Figure 1 for the acetylation of 3-APD and 2-APD on top and bottom, respectively. The three profiles shown in each plot report the GC-yields of the $\mathrm{N}$-acetylation products $\mathbf{1 a}$ and $\mathbf{2} \mathbf{a}(\mathrm{N}-(2,3-$ dihydroxypropyl)acetamide and N-(1,3-dihydroxypropan-2-yl) acetamide, respectively; Scheme 3) at 80, 90, and $100{ }^{\circ} \mathrm{C}$ (black, red, and blue curves) as a function of time. Both compounds 1a and 2a were fully characterized by GC/MS, ${ }^{1} \mathrm{H}$ and ${ }^{13} \mathrm{C}$ NMR (see experimental and SI sections, Figures S1-S6). All reactions were run in duplicate for reproducibility ensuring $<5 \%$ difference in yields between repeated tests. 


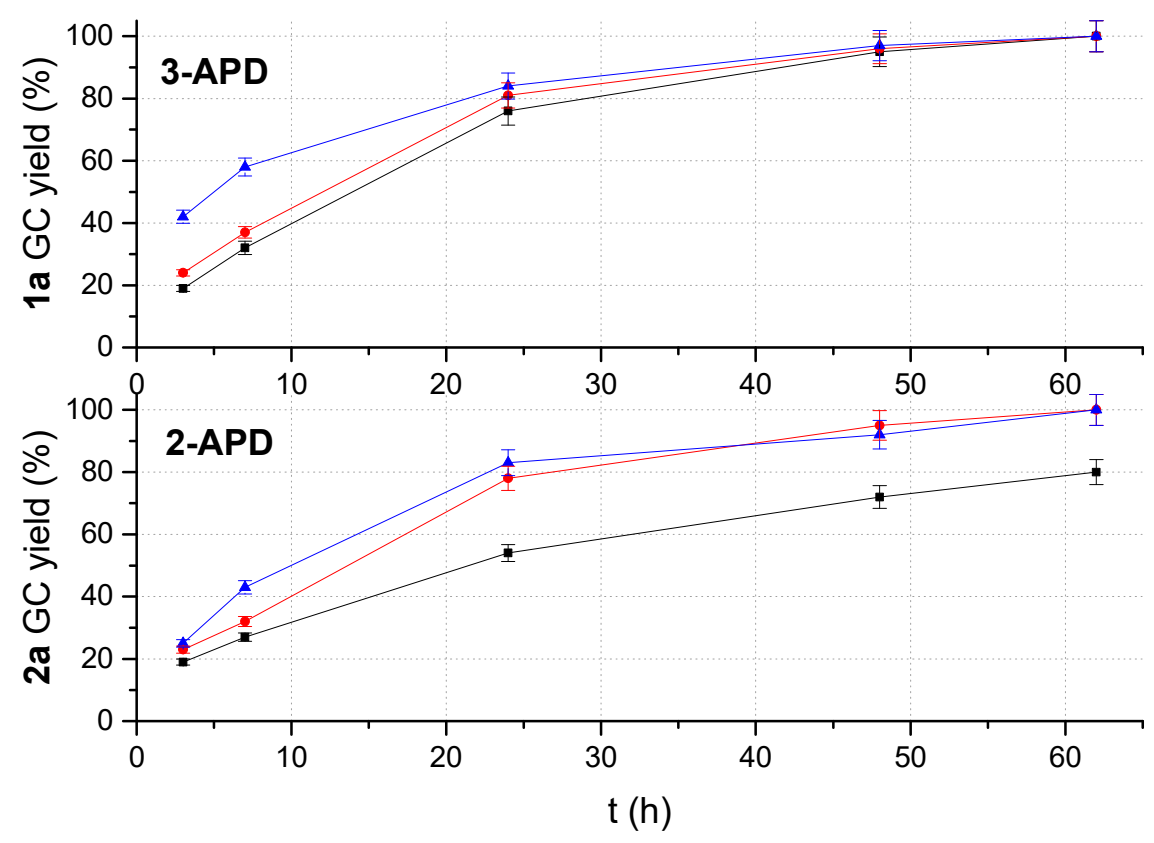

Figure 1. Batch reactions of APD isomers with iPAc. Top and bottom: GC yields of amide products 1a and 2a from 3-APD and 2-APD, respectively, at $\mathrm{T}=80^{\circ} \mathrm{C}(-\boldsymbol{-}-), 90^{\circ} \mathrm{C}(-\bullet-)$, and $100{ }^{\circ} \mathrm{C}(-\mathbf{\Delta}-)$. Other conditions: mixture of APD (1 mmol), iPAc (1.1 equivs.), and 1,4-dioxane as a solvent $(5 \mathrm{~mL})$.

Experiments demonstrated that not only the $\mathrm{N}$-acetylation reactions was effective under the chosen conditions, but it proceeded with an excellent chemoselectivity ( $>99 \%)$. Regardless of the reaction time and the temperature, amides 1a and 2a were the only observed products. This was confirmed by the match of the yields of $\mathbf{1 a}$ and $\mathbf{2 a}$ and the conversion of reagents 3- and 2-APD, both determined by GC response calibration with an internal standard. The exclusive $\mathrm{N}$-acetylation was consistent with the better nucleophilicity of the amino group of both APDs compared to the primary and secondary hydroxyls which were preserved from any reaction. Indeed, no other products were detected.

On the other hand, both the temperature and the nature of the APD isomer affected the N-acetylation kinetics. Increasing T from 80 to $100{ }^{\circ} \mathrm{C}$ resulted in a general increase of yields of amides 1a and 2a from ca. $25-30 \%$ to $45-60 \%$ in the first $6 \mathrm{~h}$. After $24 \mathrm{~h}$, however, the acetylation of 3-APD appeared slightly influenced by the temperature and it proceeded to completion in all experiments (Figure 1, top), while a slower conversion of 2-APD was noticed at $80{ }^{\circ} \mathrm{C}$, not exceeding $80 \%$ even after $62 \mathrm{~h}$ of reaction (Figure 1, bottom; black profile). The amide $2 \mathrm{a}$ was obtained in quantitative yield only at $\mathrm{T} \geq 90^{\circ} \mathrm{C}$. The higher steric hindrance of the secondary amino group of serinol with respect to primary one of 3-APD was plausibly responsible for this behavior. Overall, the optimized temperatures to continue the study of the $\mathrm{N}$-acetylation reaction were set to 80 and $90{ }^{\circ} \mathrm{C}$ for 3- and 2-APD, respectively.

The APD:iPAc molar ratio and the solvent. The effect of the iPAc:APD molar ratio $(\mathrm{Q})$ was investigated by doubling and quadrupling the molar amount of iPAc with respect to conditions of Figure 1. The increased quantity of iPAc had no adverse consequences on APDs solubilities. Additional experiments were carried out also by replacing 1,4-dioxane $(5 \mathrm{~mL})$ with DMSO $(0.5-5 \mathrm{~mL})$ as the solvent. Table 1 summarizes the results. For a convenient comparison, some results of Figure 1 are also indicated (entries 1 and 5). 
Table 1. The iPAc-mediated selective N-N-acetylation of 3- and 2-APD regioisomers.

\begin{tabular}{|c|c|c|c|c|c|c|}
\hline Entry & Substrate & $\begin{array}{c}\mathrm{T} \\
\left({ }^{\circ} \mathrm{C}\right)\end{array}$ & $\underset{(\mathrm{mol} / \mathrm{mol})}{\mathrm{Q}^{\mathrm{a}}}$ & $\begin{array}{l}\text { Solvent } \\
(\mathrm{mL})\end{array}$ & $\begin{array}{c}\text { t } \\
(\mathrm{h})\end{array}$ & $\begin{array}{c}\text { Amide } \\
\text { Yield }^{b}(\%)\end{array}$ \\
\hline 1 & \multirow{6}{*}{ 3-APD } & \multirow{6}{*}{80} & 1.1 & 1,4-dioxane (5) & 48 & 1a: $94 \%{ }^{c}$ \\
\hline 2 & & & 2.2 & 1,4-dioxane (5) & 24 & $1 a: \geq 99 \%$ \\
\hline $3^{c}$ & & & 4.4 & 1,4-dioxane (5) & 16 & $\begin{array}{c}\text { 1a: } \geq 99 \% \\
\text { Isolated: } \geq 99 \%\end{array}$ \\
\hline 4 & & & 4.4 & DMSO (5) & 3 & 1a: $\geq 99 \%$ \\
\hline 5 & & & 4.4 & DMSO (1) & 1 & 1a: $\geq 99 \%$ \\
\hline 6 & & & 4.4 & DMSO (0.5) & 0.75 & 1a: $\geq 99 \%$ \\
\hline $7^{c}$ & \multirow{6}{*}{ 2-APD } & \multirow{6}{*}{90} & 1.1 & 1,4-dioxane (5) & 62 & 2a: $\geq 99 \%$ c \\
\hline 8 & & & 2.2 & 1,4-dioxane (5) & 48 & $2 a: \geq 99 \%$ \\
\hline 9 & & & 4.4 & 1,4-dioxane (5) & 24 & $\begin{array}{c}2 \mathrm{a}: \geq 99 \% \\
\text { Isolated: } \geq 99 \%\end{array}$ \\
\hline 10 & & & 4.4 & DMSO (5) & 8 & $\mathbf{2 a}: \geq 99 \%$ \\
\hline 11 & & & 4.4 & DMSO (1) & 2.5 & $2 a: \geq 99 \%$ \\
\hline 12 & & & 4.4 & DMSO (0.5) & 2 & 2a: $\geq 99 \%$ \\
\hline
\end{tabular}

Conditions: mixture of APD (1 mmol), iPAc (1.1-4.4 equivs.), and the solvent of choice (1-5 mL): $\mathrm{T}=80$ and $90^{\circ} \mathrm{C}$ for 3-APD and 2-APD, respectively. ${ }^{\mathrm{a}}$ iPAc:APD molar ratio (Q). ${ }^{\mathrm{b}}$ Yields of amide derivatives determined by GC or after isolation of the products (entries 3 and 7). ${ }^{c}$ Results from Figure 1.

Both changes of the $Q$ ratio and the solvent did not affect the chemoselectivity which remained $>99 \%$ towards the formation of amide derivatives. However, for the reaction of 3-APD in dioxane, increasing $\mathrm{Q}$ from 1.1 to 2.2 and 4.4 induced an almost linear drop of the time for complete conversion from 48 to 24 and $16 \mathrm{~h}$, respectively (entries 1-3); while, for 2-APD, the reaction rate increased to a lesser extent consistent with the lower reactivity of this isomer (entries 7-9: time for complete reactions of 62, 48, and $24 \mathrm{~h}$ ).

Under the conditions of entries 3 and 9, two further experiments were carried out upscaling the reactants/solvent amounts by a factor of 10 (APD: $10 \mathrm{mmol}$; iPAc: $44 \mathrm{mmol}$; dioxane: $50 \mathrm{~mL}$ ). The total conversion of 3- and 2-APD required 24 and $32 \mathrm{~h}$, respectively, meaning that reactions were slower than those in Table 1; nonetheless, products $1 \mathbf{a}$ and $\mathbf{2 a}$ were easily isolated in $>99 \%$ yields and $99 \%$ purity after rotary-evaporation of the unreacted iPAc and the solvent. The latter (iPAc and dioxane) were then recovered quantitatively by fractionated distillation. Overall, the protocol proved suitable for preparative purposes on the gram scale.

The batch N-acetylation of 3- and 2-APD was then investigated using DMSO as a solvent. Compared to 1,4-dioxane $(\varepsilon=2.3, \mathrm{LD} 50=4200 \mathrm{mg} / \mathrm{kg})$, the remarkably higher polarity, the excellent $\mathrm{H}$-bonding accepting ability, and the non-toxicity of DMSO $(\varepsilon=46.7$, $\mathrm{LD} 50=14,500 \mathrm{mg} / \mathrm{kg}$ ) made it not only more efficient at solubilizing both APDs but also a greener alternative solvent [19]. A recent interesting study close to this subject inspected effects due to H-bonding in glycerol/DMSO binary mixtures [20]. Homogeneous solutions of reactants (APD: $1 \mathrm{mmol}$; iPAC: $4.4 \mathrm{mmol}$ ) were obtained by replacing dioxane either with the same volume of DMSO $(5 \mathrm{~mL})$ or by reducing the volume to 1 and $0.5 \mathrm{~mL}$, respectively. Very fast $\mathrm{N}$-acetylations were observed yielding to a quantitative formation of products $1 \mathrm{a}$ and $2 \mathbf{a}$ in all experiments. At the same concentration $(0.1 \mathrm{M}, 5 \mathrm{~mL})$, the reactions of 3-APD and 2-APD in DMSO were 16- and eight-times faster than the corresponding processes in dioxane, thereby suggesting remarkable solvation effects on the kinetics (entries 4 and 10). On the other hand, the reduction of the solvent volume brought about a further acceleration of the reactions which, again, was more pronounced for the more active 3-APD (entries 5-6 and 11-12).

Similar rapid reactions were achieved even by increasing the reactants/solvent amounts up to 10 times. Albeit attempts to isolate the products by distillation or extraction with several water/organic solvent systems failed, DMSO proved obviously advantageous from both the reaction rate and the process intensification standpoints. 
Results of Table 1 prompted us to conceive a concatenated sequence by which amides 1a and 2a, once prepared in either dioxane or DMSO, could be further converted into higher acetal homologues. The new products were expected to be quite less polar than amides and APDs, and so they could be more easily separated and handled. Flow chemistry appeared the best option to implement the second functionalization step.

\subsection{The Continuous Flow (CF) Acetalization of APD-Amides under Acid Catalysis}

\subsubsection{CF-Synthesis of N-((2,2-Dimethyl-1,3-Dioxolan-4-yl)Methyl)Acetamide (1b)}

Experiments were designed based on our previous results on the upgrading of glycerol via either sequential transesterification and acetalization processes (tandem) (Scheme 1 [18]) and CF-acetalization [21] Among available catalysts for such reactions, solid acids were the most suited systems to cope with issues of deterioration and deactivation of flow reactors and catalytic beds, co-formation of water and not least in the case of glycerol and its derivatives, clogging due to the viscosity of the solutions of reactants and products. Accordingly, three heterogenous catalysts including an organic resin as Amberlyst-15 (A15), and two inorganic solids as aluminum fluoride trihydrate $\left(\mathrm{AlF}_{3} \cdot 3 \mathrm{H}_{2} \mathrm{O}: \mathrm{AF}\right)$ and an acid exchanged Y-zeolite (HY) were chosen and compared in this study. Both A15 and AF were commercially available compounds, while $\mathrm{HY}$ was obtained by calcination of a $\mathrm{NH}_{4} \mathrm{Y}$ faujasite through a procedure reported elsewhere [22].

Acetone as a Reagent and a Solvent/Carrier

Initial tests were carried out using a $0.1 \mathrm{M}$ solution of amide $\mathbf{1 a}$ (prepared as described in Table 1) in acetone that acted as a reagent and a solvent/carrier. This mixture was continuously conveyed to a cylindrical steel reactor $(\mathrm{L} \times \mathrm{D}=12 \mathrm{~mm} \times 6 \mathrm{~mm}$, internal volume $=1.4 \mathrm{~mL}$ ) filled with the catalyst (Amberlyst- 15 or $\mathrm{AlF}_{3} \cdot 3 \mathrm{H}_{2} \mathrm{O}$ or $\mathrm{HY}: 0.8 \mathrm{~g}$ in each case. Further details on the CF apparatus are in the SI section, Figure S7). The temperature, the pressure, and the flow rate $(\mathrm{F})$ were varied in the range of $30-150{ }^{\circ} \mathrm{C}, 1-20 \mathrm{~atm}$, and 0.1-0.2 $\mathrm{mL} \mathrm{min}^{-1}$, respectively. Most representative results are reported in Table 2 and refer to reactions run for $5 \mathrm{~h}$.

Table 2. The CF-acetalization of amide 1a over different catalysts.

\begin{tabular}{|c|c|c|c|c|c|c|}
\hline Entry & Catalyst $^{a}$ & $\begin{array}{c}\mathrm{T} / \mathrm{p} \\
\left({ }^{\circ} \mathrm{C} / \mathrm{b} \text { ar }\right)\end{array}$ & $\begin{array}{c}\text { Flow } \\
(\mathrm{mL} / \mathrm{min})\end{array}$ & $\begin{array}{l}\text { Conv. } \\
(\%)^{b}\end{array}$ & $\begin{array}{l}\text { Sel. } \\
(\%)^{b}\end{array}$ & $\begin{array}{c}\text { Mass } \\
\text { Balance (\%) }\end{array}$ \\
\hline 1 & \multirow{2}{*}{ A15 } & \multirow{2}{*}{$30 / 1$} & 0.1 & $>99$ & $>99$ & \multirow{4}{*}{$\begin{array}{l}>99 \\
>99\end{array}$} \\
\hline 2 & & & 0.2 & $>99$ & $>99$ & \\
\hline 3 & \multirow{2}{*}{$\mathrm{AF}$} & $100 / 20$ & 0.2 & 40 & 96 & \\
\hline 4 & & $150 / 20$ & 0.2 & 79 & 99 & \\
\hline 5 & \multirow{2}{*}{$\mathrm{HY}$} & $100 / 20$ & 0.2 & 27 & 92 & \multirow{2}{*}{ nd } \\
\hline 6 & & $150 / 20$ & 0.2 & 76 & 91 & \\
\hline
\end{tabular}

All reactions were carried using a $0.1 \mathrm{M}$ solution of amide 1a in acetone. ${ }^{a}$ A15: Amberlyst-15; AF: $\mathrm{AlF}_{3} \cdot 3 \mathrm{H}_{2} \mathrm{O}$; HY. In each case, the same amount of catalyst was used $(0.8 \mathrm{~g}) .{ }^{\mathrm{b}}$ Conversion of amide $\mathbf{1 a}$ and selectivity towards N-(1,3-dihydroxypropan-2-yl) acetamide $\mathbf{1 b}$, both determined by GC/MS. ${ }^{c}$ Mass balance evaluated from the recovery of the mixture of the reactor outlet and the isolation of the product. nd: not determined.

CF-tests proved the feasibility of the CF-acetalization of amide 1a, though significantly different outcomes were observed by changing the catalyst. With respect to AF and HY, A15 was a far more active system allowing the acetalization reaction to proceed at $30{ }^{\circ} \mathrm{C}$ and atmospheric pressure with excellent conversion and selectivity towards acetal $\mathbf{1} \mathbf{b}$, both higher than $99 \%$ (entries 1-2). Other solid catalysts instead, were effective only at temperatures of $100-150{ }^{\circ} \mathrm{C}$ that required to operate under pressure (20 bar) to keep acetone in a condensed phase. Notwithstanding these harsher conditions, the conversion of amide 1a did not exceed 79 and $76 \%$ at $150{ }^{\circ} \mathrm{C}$ using AF and HY, respectively (entries 4 and 6). This trend was in line with the results of our previous study on the acetalization of glycerol 
that demonstrated a comparatively better performance of Amberlyst 36 with respect to $\mathrm{AlF}_{3} \cdot 3 \mathrm{H}_{2} \mathrm{O}[21]$.

In the case of the reaction catalyzed by $\mathrm{A} 15$, after $5 \mathrm{~h}$ at $\mathrm{F}=0.1 \mathrm{~mL} \mathrm{~min} \mathrm{~m}^{-1}$, the volume of the solution collected at the reactor outlet was $30 \mathrm{~mL}$ (>99\% of the expected value) and the yield of crude acetal $\mathbf{1 b}$ isolated after rotary evaporation of acetone was $99 \%$ (518 mg) (entry 1). ${ }^{1} \mathrm{H}$ NMR confirmed that the purity of the product (1b) was $>95 \%$ (Figures S1 and S2 in the SI section). The same volume/yield correspondence was achieved when $\mathrm{F}$ was doubled at $0.2 \mathrm{~mL} \mathrm{~min}^{-1}$ (entry 2). These results validated the mass balance of the CF-process and ruled out the occurrence of side-reactions.

Under the conditions of entries $1-2\left(30^{\circ} \mathrm{C}, 1 \mathrm{~atm}\right)$ further experiments were then performed to investigate the effect of the flow rate by changing it in a relatively wide range from 0.1 to $1.5 \mathrm{~mL} \mathrm{~min}^{-1}$. Results are shown in Figure 2.

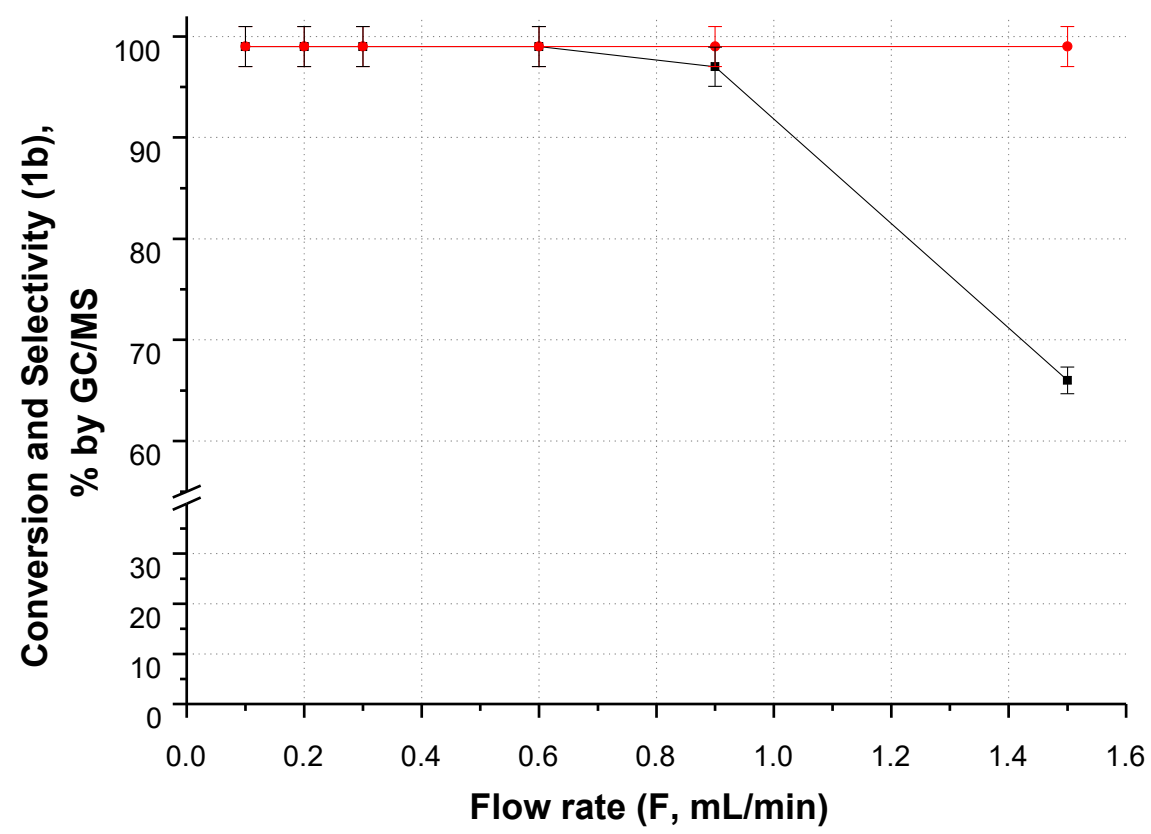

Figure 2. The effect of the flow rate (F) on CF-acetalization of amide 1a. Other conditions were those of entries 1-2 in Table $1: 30{ }^{\circ} \mathrm{C}, 1 \mathrm{~atm}, \mathrm{~A} 15$ catalyst $(0.8 \mathrm{~g}), 0.1 \mathrm{M}$ solution of $1 \mathrm{a}$ in acetone. (-口-) 1a conversion; (-๑-) $\mathbf{1 b}$ selectivity.

The formation of acetal $\mathbf{1 b}$ took place with selectivity $>99 \%$ regardless of the set flow rate (red profile). The conversion of amide 1a was steady at a quantitative value until F was $\leq 0.6 \mathrm{~mL} \mathrm{~min}^{-1}$; then, it (conversion) showed a slight decrease to $95 \%$ and a more pronounced drop to $66 \%$ at $\mathrm{F}=0.9$ and $1.5 \mathrm{~mL} \mathrm{~min}^{-1}$, respectively (black profile). Results demonstrated that the acetalization protocol was highly efficient throughout the investigated range of $\mathrm{F}$ : by reducing the contact time $(\tau)$ from $14 \mathrm{~min}\left(\mathrm{~F}=0.1 \mathrm{~mL} \cdot \mathrm{min}^{-1}\right)$ to $0.9 \mathrm{~min}\left(\mathrm{~F}=1.5 \mathrm{~mL} \cdot \mathrm{min}^{-1}\right)$, the specific productivity (WHSV) was enhanced by a factor of 10, from 0.13 up to $1.3 \mathrm{~g} /\left(\mathrm{g}_{\text {cat }} \mathrm{h}\right)$. An additional prolonged test run for $10 \mathrm{~h}$ at $\mathrm{F}=0.1 \mathrm{~mL} \cdot \mathrm{min}^{-1}$, proved the (long-term) stability of the catalyst: both conversion $(>99 \%)$ and selectivity (>99\%) did not show any appreciable change with respect to results of Figure 2.

Dioxane and DMSO as Solvents / Carriers

A concatenated sequence was then investigated with the aim to convert directly the crude amide $\mathbf{1 a}$ as achieved from the batch $\mathrm{N}$-acetylation, into the corresponding acetal $\mathbf{1 b}$ in the flow mode. Once the reaction of 3-APD with iPAc (in a 1:4 molar ratio) was carried out under the conditions of entries 3 and 4 in Table 1 , the resulting solution of amide 1a $(0.2 \mathrm{M})$ plus unconverted iPAc in dioxane or DMSO solvent, was added with different 
amounts of acetone $\left(Q_{1}=\right.$ Ace:1a $\left.=5-40 \mathrm{~mol}: \mathrm{mol}\right)$. Without any further treatment, the mixture was used to feed the CF-reactor, by continuously conveying it to a catalytic bed of Amberlyst-15 (0.8 g). All CF-experiments were run for $5 \mathrm{~h}$ at atmospheric pressure through the same procedure and apparatus described in Table 2 and Figure 2. The temperature and the flow rate were changed in the range of $30-50{ }^{\circ} \mathrm{C}$, and $0.1-0.6 \mathrm{~mL} \mathrm{~min}^{-1}$, respectively. Results are reported in Table 3.

Table 3. The concatenated sequence: CF-acetalization of crude amide 1a in the presence of dioxane or DMSO solvent ${ }^{\mathrm{a}}$.

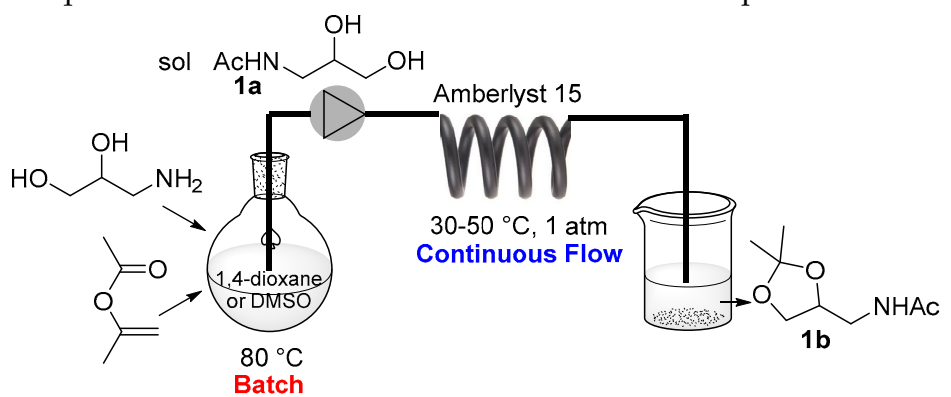

\begin{tabular}{|c|c|c|c|c|c|c|}
\hline Entry & $\begin{array}{l}\text { Ace: } 1 \mathrm{a}, \mathrm{Q}_{1} \\
\text { (mol:mol) }\end{array}$ & Solvent & $\begin{array}{c}\mathrm{T} / \mathrm{p} \\
\left({ }^{\circ} \mathrm{C} / \mathrm{bar}\right)\end{array}$ & $\begin{array}{c}\text { Flow } \\
(\mathrm{mL} / \mathrm{min})\end{array}$ & $\begin{array}{l}\text { Conv. } \\
(\%)^{c}\end{array}$ & $\begin{array}{r}\text { Sel. } \\
(\%)\end{array}$ \\
\hline 1 & \multirow{2}{*}{5} & \multirow{2}{*}{ 1,4-Dioxane } & $30 / 1$ & 0.1 & 33 & 94 \\
\hline 2 & & & $50 / 1$ & 0.1 & 73 & 91 \\
\hline 3 & \multirow{3}{*}{20} & \multirow{3}{*}{ 1,4-Dioxane } & \multirow{3}{*}{$30 / 1$} & 0.1 & 83 & $>99$ \\
\hline 4 & & & & 0.3 & 61 & $>99$ \\
\hline 5 & & & & 0.6 & 53 & $>99$ \\
\hline 6 & \multirow{2}{*}{40} & \multirow{2}{*}{ 1,4-Dioxane } & \multirow{2}{*}{$30 / 1$} & 0.1 & 95 & $>99$ \\
\hline 7 & & & & 0.3 & 86 & $>99$ \\
\hline 8 & \multirow{2}{*}{40} & \multirow{2}{*}{ DMSO } & $30 / 1$ & \multirow{2}{*}{0.3} & 11 & 88 \\
\hline 9 & & & $50 / 1$ & & 32 & 92 \\
\hline
\end{tabular}

All reactions were carried using a $0.2 \mathrm{M}$ solution of amide 1a in dioxane (entries 1-7) or DMSO (entries 7-8), in the presence of added acetone. ${ }^{a}$ The catalytic bed was made up of Amberlyst-15 (0.8 g). ${ }^{b}$ Molar ratio of acetone and $1 \mathrm{a}\left(\mathrm{Q}_{1}\right) .{ }^{\mathrm{c}} \mathrm{Conversion}$ of amide $1 \mathrm{a}$ and selectivity towards N-(1,3-dihydroxypropan-2-yl) acetamide $\mathbf{1 b}$, both determined by GC/MS.

Tests demonstrated that the concatenated protocol was successfully implemented in dioxane as a solvent. Notwithstanding the presence of residual iPAc in the reacting mixture, the competitive acid-catalyzed transesterification of hydroxyl groups of amide 1a took place to a very minor extent or was not observed at all, it even at a high/quantitative conversion: the acetal was obtained on an exclusive basis $(>99 \%)$ in the presence of $\geq 20$ molar equivs of acetone (entries 3-7); while, if the Q1 ratio was reduced to 5, the selectivity towards compound $\mathbf{1 b}$ decreased to $91-94 \%$ due to the concurrent formation of O-acetyl derivatives of 1a (6-9\%) (entries 1-2; other details are in the SI section, Figure S11). A similar remarkable preference for the acetalization with respect to the transesterification process was noticed by us also during previous studies on the tandem reactions of diols mediated by iPAc [17]. This behavior was consistent with the higher reactivity of carbonyl compounds compared to esters toward nucleophilic additions/substitutions.

Albeit the $\mathrm{Q}_{1}$ molar ratio (acetone:1a) had no or little effect on selectivity, it significantly altered the kinetics. At $\mathrm{T}=30{ }^{\circ} \mathrm{C}, \mathrm{p}=1 \mathrm{~atm}$, and $\mathrm{F}=0.1 \mathrm{~mL} \mathrm{~min}^{-1}$, a progressive improvement of the reaction conversion from 33\% up to a nearly quantitative value (95\%) was observed when the excess acetone was increased from 5 to 40 equivs. (entries 1, 3, and 6). These experiments also confirmed the results of Figure 2, further demonstrating that changing the flow rate greatly enhanced the reaction productivity. For example, at $Q_{1}=20$ and 40 , by triplicating F from 0.1 to $0.3 \mathrm{~mL} \mathrm{~min}^{-1}$, WHSV was improved from 0.21 to 0.45 and 0.18 to $0.48 \mathrm{~g} /\left(\mathrm{g}_{\text {cat }} \mathrm{h}\right.$, respectively (entries $3-4$ and $\left.6-7\right)$.

A strikingly poor result was instead obtained using the crude amide 1a in DMSO solvent. After addition of acetone (40 equivs with respect to 1a), when the mixture was set 
to react in the flow mode at $\mathrm{T}=30^{\circ} \mathrm{C}$ and $\mathrm{F}=0.3 \mathrm{~mL} \mathrm{~min}^{-1}$, the conversion was as low as $11 \%$ (entry 8 ). This (conversion) only slightly improved to $32 \%$ at $50{ }^{\circ} \mathrm{C}$. The acetalization selectivity did not exceed $92 \%$ due to competitive formation of acetate derivatives of amide 1a (Figure S11). Further investigations of this behavior were beyond the scope of the present paper; though, among plausible reasons for the adverse influence of DMSO on the acetalization kinetics, it was postulated that the occurrence of a strong (mostly $\mathrm{H}$-bonding) interaction between DMSO and $\mathrm{OH}$ groups of the amide 1a played a role in disfavoring/inhibiting the reaction [20]. Solvent effects on the catalyst (A15) seemed less plausible since, for example, it was demonstrated that 1,4-dioxane and DMSO induced a comparable swelling on different Amberlyst solids [23].

\subsubsection{CF-Synthesis of N-(2,2-Dimethyl-1,3-Dioxan-5-yl)Acetamide (2b)}

Experiments were carried out either using a $0.1 \mathrm{M}$ solution of (purified) amide 2a in acetone as a reagent/solvent, or a $0.2 \mathrm{M}$ solution of crude amide $2 \mathbf{a}$ as obtained from the $\mathrm{N}$-acetylation reaction with iPAc in the presence of dioxane solvent (entry 7, Table 1). In the latter case, acetone was added in 40 molar equivs with respect to 2a. Other conditions were set according to the results optimized for amide 1a (Table 2, Figure 2 and Table 3):

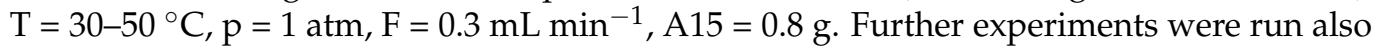
at $100{ }^{\circ} \mathrm{C}$ and 10 bar. Table 4 reports the reaction conversion and the selectivity towards acetals $\mathbf{2 b}$ after $5 \mathrm{~h}$.

Table 4. The CF-acetalization of amide $2 a^{a}$.

\begin{tabular}{|c|c|c|c|c|}
\hline Entry & Solvent & $\begin{array}{c}\mathrm{T} / \mathrm{p} \\
\left({ }^{\circ} \mathrm{C} / \mathrm{b} \text { ar }\right)\end{array}$ & $\begin{array}{l}\text { Conv. } \\
(\%)^{b}\end{array}$ & $\begin{array}{l}\text { Sel. } \\
(\%)^{b}\end{array}$ \\
\hline 1 & \multirow{3}{*}{ acetone } & $30 / 1$ & 24 & 94 \\
\hline 2 & & $50 / 1$ & 37 & 95 \\
\hline 3 & & $100 / 10$ & 62 & 92 \\
\hline 4 & \multirow{3}{*}{ 1,4-Dioxane } & $30 / 1$ & 15 & 96 \\
\hline 5 & & $50 / 1$ & 24 & 97 \\
\hline 6 & & $100 / 10$ & 87 & 43 \\
\hline 7 & \multirow{2}{*}{ DMSO } & $30 / 1$ & 11 & 17 \\
\hline 8 & & $50 / 1$ & 18 & 45 \\
\hline
\end{tabular}

CF-reactions were carried using a $0.1 \mathrm{M}$ solution of amide $2 \mathrm{a}$ in acetone (entries 1-1) or a $0.2 \mathrm{M}$ solution of 2a in 1,4-dioxane (entries 3-4) or DMSO (entries 5-6) in the presence of added acetone (40 molar equivs with respect to 2a). ${ }^{a}$ The catalytic bed was made up of Amberlyst-15 (0.8 g). ${ }^{\mathrm{b}}$ Conversion of amide $\mathbf{2 a}$ and selectivity towards N-(2,2-dimethyl-1,3-dioxan-5-yl)acetamide $\mathbf{2 b}$, both determined by GC/MS.

The acetalization of amide $\mathbf{2 a}$ was far more difficult than amide $\mathbf{1 a}$, in line with the higher stability expected for the five- versus the six-membered ring cyclic acetal [24]. At atmospheric pressure, even increasing the temperature from 30 to $50{ }^{\circ} \mathrm{C}$, the conversion did not exceed $37 \%$ and $24 \%$ in the presence of acetone alone (entries 1-2) and in dioxane solvent (entries $4-5$ ), respectively. The formation of acetal $\mathbf{2 b}(\geq 94 \%)$ was almost exclusive. Increasing the temperature to $100{ }^{\circ} \mathrm{C}$ greatly improved the reaction outcome in acetone, with conversion and selectivity of 62 and $92 \%$, respectively (entry 3). A significant change was, however, noticed for the concatenated sequence: in the presence of iPAc, competitive acetalization and transesterification of $\mathbf{2} \mathbf{a}$ took place yielding product $\mathbf{2} \mathbf{b}(43 \%)$ along with mono- and di-acetate esters of the reactant amide in 16 and $41 \%$ selectivity, respectively (entry 6). Under such conditions, the pressure was set to 10 bar to allow acetone reacting in a condensed phase [24]. The acetal $\mathbf{2} \mathbf{b}$ was fully characterized by ${ }^{1} \mathrm{H}-$ and ${ }^{13} \mathrm{C}-\mathrm{NMR}$, and GC/MS (Figures S12-S14), while the structure of acetate side-products was assigned by GC/MS (Figure S15-16).

The use of DMSO solvent was always detrimental. The conversion was as low as $11-18 \%$ and acetate esters of $\mathbf{2} \mathbf{a}$ were the predominant products (entries $7-8$ ). 


\section{Materials and Methods}

\subsection{General}

Reagents and solvents were commercially available compounds and were used as received unless otherwise stated. 3-amino-1,2-propanediol, 2-amino-1,3-propanediol, isopropenyl acetate, 1,4-dioxane, dimethyl sulfoxide, ethanol, acetone, Amberlyst-15, $\mathrm{AlF}_{3} \cdot 3 \mathrm{H}_{2} \mathrm{O}$ were sourced from Sigma Aldrich (now Merck Life Science S.r.l., Milano, IT). Zeolite HY HY was obtained by calcination of a commercial $\mathrm{NH}_{4} \mathrm{Y}$ solid [20]. GC/MS and GC/FID (EI, $70 \mathrm{eV}$ ) analyses were performed on HP-35 and ELITE-624, respectively, capillary columns $(\mathrm{L}=30 \mathrm{~m}, \varnothing=0.32 \mathrm{~mm}$, film $=0.25 \mathrm{~mm}) .{ }^{1} \mathrm{H}$ and ${ }^{13} \mathrm{C}$ NMR spectra were recorded at 400 and $100 \mathrm{MHz}$, respectively. The chemical shifts were reported downfield from tetramethylsilane (TMS), and $\mathrm{CDCl}_{3}, \mathrm{CD}_{3} \mathrm{OD}$ or $\mathrm{d}_{6}$-DMSO were used as the solvent, depending on the compounds solubility.

\subsection{General Procedure for the Batch N-Acetylation of 3-APD and 2-APD (Serinol)}

Experiments were carried out under the conditions described in Table 1 and Figure 1. In a typical procedure, a 10-mL round-bottomed flask, equipped with a condenser and a magnetic stir bar, a mixture of 3-amino-1,2-propanediol (APD) or 2-amino-1,3-propanediol (serinol) (1 mmol), iPAc (1.1-4.4 equivs.), and 1,4-dioxane $(5 \mathrm{~mL})$ or DMSO $(0.5-5 \mathrm{~mL})$ as a solvent was set to react at $\mathrm{T}=80-90{ }^{\circ} \mathrm{C}$ and atmospheric pressure, for 1-62 $\mathrm{h}$. Conversion of APDs and products selectivity were determined by GC-FID analysis upon calibration.

The same procedure was also scaled up by a factor of 10, using a mixture of the selected APD (10 mmol), isopropenyl acetate (4.4 equivs.), and 1,4-dioxane as a solvent $(50 \mathrm{~mL})$. Once the experiment was complete, the excess of solvent and iPAc was distilled off by vacuum evaporation, affording the $\mathrm{N}$-(2,3-dihydroxypropyl)acetamide (1a) or $\mathrm{N}-(1,3-$ dihydroxypropan-2-yl)acetamide (2a) in quantitative yields. In addition, the recovery of the iPAc was performed by vacuum fractionated distillation. Products $\mathbf{1 a}$ and $\mathbf{1 b}$ were isolated and fully characterized by MS $(70 \mathrm{eV}),{ }^{1} \mathrm{H}$ NMR, and ${ }^{13} \mathrm{C}$ NMR. Spectra are reported in the SI section.

\subsection{General Procedure for the CF Acetalization of Amides $1 a, 2 a$}

Experiments were performed using an in-house assembled continuous-flow (CF) apparatus (see SI, Figure S7), under the conditions described in Tables $2-4$ and Figure 2. In a typical procedure, the $\mathrm{CF}$ apparatus was conditioned with acetone $\left(30 \mathrm{~mL}\right.$ at $\left.5 \mathrm{~mL} \cdot \mathrm{min}^{-1}\right)$. Then, a homogeneous $0.1 \mathrm{M}$ solution of the reactants (amides 1a, 2a) in acetone, acetone/dioxane, acetone/DMSO was delivered to the catalytic bed of choice (Amberlyst $15, \mathrm{AlF}_{3} \cdot 3 \mathrm{H}_{2} \mathrm{O}$, or HY: $0.8 \mathrm{~g}$ in each case) at the desired $\mathrm{T}, \mathrm{p}$, and flow rates $\left(30-100{ }^{\circ} \mathrm{C}, 1-10 \mathrm{bar}\right.$, and $0.1-1.5$ $\left.\mathrm{mL} \cdot \mathrm{min}^{-1}\right)$. Aliquots $(0.3 \mathrm{~mL})$ of the reaction mixture were sampled at the outlet of the reactor every $30 \mathrm{~min}$ and analyzed by GC/MS. Reactions were allowed to proceed for $5 \mathrm{~h}$, though some prolonged tests were carried out for up to $12 \mathrm{~h}$.

Acetal products $\mathbf{1 b}$ and $\mathbf{2 b}$ were isolated according to the following procedure. Compound $1 \mathbf{b}$ was directly isolated in $>99 \%$ yield and very high purity $(>96 \%, \mathrm{GC})$ after simple rotary-evaporation of excess acetone and the solvent (dioxane, if present). Compound $\mathbf{2 b}$ instead, after rotary-evaporation of the final reaction mixture, was isolated by FCC (stationary phase: $\mathrm{SiO}_{2}$; eluent: $\mathrm{Et}_{2} \mathrm{O}$ ) in $49 \%$ yield. Products were characterized both by MS $(70 \mathrm{eV}),{ }^{1} \mathrm{H}$ NMR, and ${ }^{13} \mathrm{C}$ NMR. Spectra are reported in the SI section.

\section{Conclusions}

The present paper describes an original protocol demonstrating how a catalyst-free $\mathrm{N}$-acetylation reaction carried out under batch conditions, can be efficiently concatenated to a continuous-flow acid-catalyzed acetalization process for the upgrading of aminodiol regioisomers (APDs) of glycerol. A double functionalization of APDs is achieved through the proposed strategy: reagents are first converted into the corresponding $\mathrm{N}$-acetyl derivatives which without isolation, are further transformed to cyclic C5 and C6 acetal homologues, though, only through a careful choice of reaction conditions, both steps ( $\mathrm{N}$-acetylation and 
acetalization) were successful. In addition to the optimization of the temperature, aspects highlighted by this study especially include the role/effect of: (i) the solvent for the batch $\mathrm{N}$-acetylation which is critical to obtain homogenous solutions of hardly soluble substrates as APDs; (ii) the nature of the solvent/catalyst and the reagent (amide):acetone molar ratio which affect the conversion and steer the selectivity of the CF-acetalization.

Of the two identified solvents, DMSO and 1,4-dioxane, the former is far more efficient at solubilizing APDs, but it fails as an acetalization solvent probably because of strong (H-bonding) solvation effects of amide reactants. The less polar and lower boiling dioxane, albeit implying longer reaction times and the use of diluted solutions, has proved to be suitable for the concatenated procedure, allowing also a facile separation of both amides and acetals derivatives. In line with previous studies on the acetalization of glycerol, this study confirms that acid organic resins, specifically Amberlyst 15 (A15) shows a far better performance than other solid catalysts (faujasite $(\mathrm{HY})$ and $\mathrm{AlF}_{3} \cdot 3 \mathrm{H}_{2} \mathrm{O}$ ) for the $\mathrm{CF}$ conversion of APD-derived amides into the corresponding acetals. Beyond advantages of A15 in terms of reduced equipment corrosion and environmental acceptability, the flow protocol can be easily tuned to improve the reaction productivity which for the case of acetal $\mathbf{1 b}$, was enhanced to 1.3 and $0.48 \mathrm{~g} /\left(\mathrm{g}_{\text {cat }} \mathrm{h}\right)$ in acetone and in dioxane solvent, respectively.

A conclusive note is the remarkably different behavior of amide $1 \mathbf{a}$ and $\mathbf{2 a}$ towards acetalization, being the former much more active than the latter, with consequences not only on the reaction rate but also on the products distribution. The five-membered ring product $\mathbf{1 b}$ is achieved with $>99 \%$ selectivity, while the formation of the less stable sixmembered cyclic acetal $\mathbf{2} \mathbf{b}$ is always accompanied by a competitive transesterification process.

Supplementary Materials: The following are available online at https:/ / www.mdpi.com/2073-434 $4 / 11 / 1 / 21 / \mathrm{s} 1$.

Author Contributions: Conceptualization: M.S. and D.R.; methodology: D.R.; validation: M.S., D.R.; investigation: D.R and N.A.C.D.S.; resources: M.S.; writing-original draft preparation: D.R. and M.S.; writing-review and editing: D.R., M.S., and A.P.; funding acquisition: M.S. and A.P. All authors have read and agreed to the published version of the manuscript.

Funding: This research received no external funding.

Institutional Review Board Statement: The study was conducted according to the guidelines of the Declaration of Helsinki, and approved by the Ethics Committee of University Ca' Foscari Venezia, Italy (protocol code D.R. 1116 date 05/11/2019).

Informed Consent Statement: Informed consent was obtained from all subjects involved in the study.

Data Availability Statement: The data presented in this study are openly available in [repository name e.g., FigShare] at [doi], reference number [reference number].

Acknowledgments: The authors thank Sofia Novaselich for her help in the batch reactivity experiments.

Conflicts of Interest: The authors declare no conflict of interest.

\section{References}

1. Liang, G.; Wang, A.; Li, L.; Xu, G.; Yan, N.; Zhang, T. Production of Primary Amines by Reductive Amination of Biomass-Derived Aldehydes/Ketones. Angew. Chem.-Int. Ed. 2017, 56, 3050-3054. [CrossRef] [PubMed]

2. Horiguchi, A.; Takabe, A.; Takemoto, E. A Process for the Preparation of a Dihydroxyamino Compound. EP1201644 (A2), 2 May 2002.

3. Felder, E.; Roemer, M.; Bardonner, H.; Haertner, H.; Fruhstorfer, W. Process for the Preparation of Hydroxyamines. US5023379 (A), 11 June 1991.

4. Borregaard, A.; Tjosaas, F. Process for the Production of Amino Alcohols. WO2012108777 (A1), 16 August 2012.

5. Baum, K.; Maurice, W.T. The Mannich Condensation of 3-amino-1,2-propanediol with 2,2-dinitropropanol and the nitration of the product. J. Org. Chem. 1962, 27, 2231-2233. [CrossRef]

6. Andreeßen, B.; Steinbüchel, A. Serinol: Small molecule-big impact. AMB Express 2011, 1, 1-6. [CrossRef] [PubMed] 
7. Cerioli, L.; Planchestainer, M.; Cassidy, J.; Tessaro, D.; Paradisi, F. Characterization of a novel amine transaminase from Halomonas elongata. J. Mol. Catal. B Enzym. 2015, 120, 141-150. [CrossRef]

8. Hegde, S.; Zhao, L. Process for Production of Serinol and Its Bis-Adduct. US8653306 (B1), 18 February 2014.

9. Cespi, D.; Cucciniello, R.; Ricciardi, M.; Capacchione, C.; Vassura, I.; Passarini, F.; Proto, A. A simplified early stage assessment of process intensification: Glycidol as a value-added product from epichlorohydrin industry wastes. Green Chem. 2016, 18, 4559-4570. [CrossRef]

10. Fedorov, A.L.; Davidenko, T.I.; Kotlyar, I.I.; Kuznetsov, V.V. Reduction of nitro groups in aliphatic compounds. Russ. J. Org. Chem. 1982, 18, 1161.

11. Felder, E.; Bianchi, S.; Bollinger, H. Process for the Preparation of Serinol and of Serinol Derivatives, and Products Obtained Therefrom. US Patent 4503252 (A), 5 March 1985.

12. Nardi, A.; Villa, M. Process for the Preparation of 2 amino-1,3-propanediol. US Patent 5922917 (A), 13 July 1999.

13. Guidi, S.; Calmanti, R.; Noè, M.; Perosa, A.; Selva, M. Thermal (catalyst-free) transesterification of diols and glycerol with dimethyl carbonate: A flexible reaction for batch and continuous-flow applications. ACS Sustain. Chem. Eng. 2016, 4, 6144-6151. [CrossRef]

14. Fiorani, G.; Perosa, A.; Selva, M. Dimethyl carbonate: A versatile reagent for a sustainable valorization of renewables. Green Chem. 2018, 20, 288-322. [CrossRef]

15. Pelagalli, R.; Chiarotto, I.; Feroci, M.; Vecchio, S. Isopropenyl acetate, a remarkable, cheap and acylating agent of amines under solvent- and catalyst-free conditions: A systematic investigation. Green Chem. 2012, 14, 2251-2255. [CrossRef]

16. Rigo, D.; Fiorani, G.; Perosa, A.; Selva, M. Acid-Catalyzed Reactions of Isopropenyl Esters and Renewable. Diols: A 100\% Carbon Efficient Transesterification/Acetalization Tandem Sequence, from Batch to Continuous Flow. ACS Sustain. Chem. Eng. 2019, 7, 18810-18818. [CrossRef]

17. Rigo, D.; Calmanti, R.; Perosa, A.; Selva, M. A transesterification-acetalization catalytic tandem process for the functionalization of glycerol: The pivotal role of isopropenyl acetate. Green Chem. 2020, 22, 5487-5496. [CrossRef]

18. Rui Faria, P.V.; Pereira, C.S.M.; Silva, V.M.T.M.; Loureiro, J.M.; Rodrigues, E.A. Glycerol valorisation as biofuels: Selection of a suitable solvent for an innovative process for the synthesis of GEA. Chem. Eng. J. 2013, 233, 159-167. [CrossRef]

19. Angulo, G.; Brucka, M.; Gerecke, M.; Grampp, G.; Jeannerat, D.; Milkiewicz, J.; Mitrev, Y.; Radzewicz, C.; Rosspeintner, A.; Vautheyf, E.; et al. Characterization of dimethylsulfoxide/glycerol mixtures: A binary solvent system for the study of "friction-dependent" chemical reactivity. Phys. Chem. Chem. Phys. 2016, 18, 18460-18469. [CrossRef] [PubMed]

20. Guidi, S.; Noè, M.; Riello, P.; Perosa, A.; Selva, M. Towards a Rational Design of a Continuous-Flow Method for the Acetalization of Crude Glycerol: Scope and Limitations of Commercial Amberlyst 36 and $\mathrm{AlF}_{3} \cdot 3 \mathrm{H}_{2} \mathrm{O}$ as Model Catalysts. Molecules 2016, 21, 657. [CrossRef] [PubMed]

21. Zhang, K.; Huang, C.; Zhang, H.; Xiang, S.; Liu, S.; Xu, D.; Li, H. Alkylation of phenol with tert-butyl alcohol catalysed by zeolite Hß. Appl. Catal. 1998, 166, 89-95. [CrossRef]

22. Mun, D.; Huynh, N.T.T.; Shin, S.; Kim, Y.J.; Kim, S.; Shul, Y.-J.; Cho, J.K. Facile isomerization of glucose into fructose using anion-exchange resins in organic solvents and application to direct conversion of glucose into furan compounds. Res. Chem. Intermed. 2017, 43, 5495-5506. [CrossRef]

23. Trifoia, A.R.; Agachib, P.S.; Pap, T. Glycerol acetals and ketals as possible diesel additives. A review of their synthesis protocols. Renew. Sustain. Energy Rev. 2016, 62, 804-814. [CrossRef]

24. Available online: https://webbook.nist.gov/ (accessed on 30 November 2020). 